\title{
Nemanich Leads Executive Committee in 1998
}

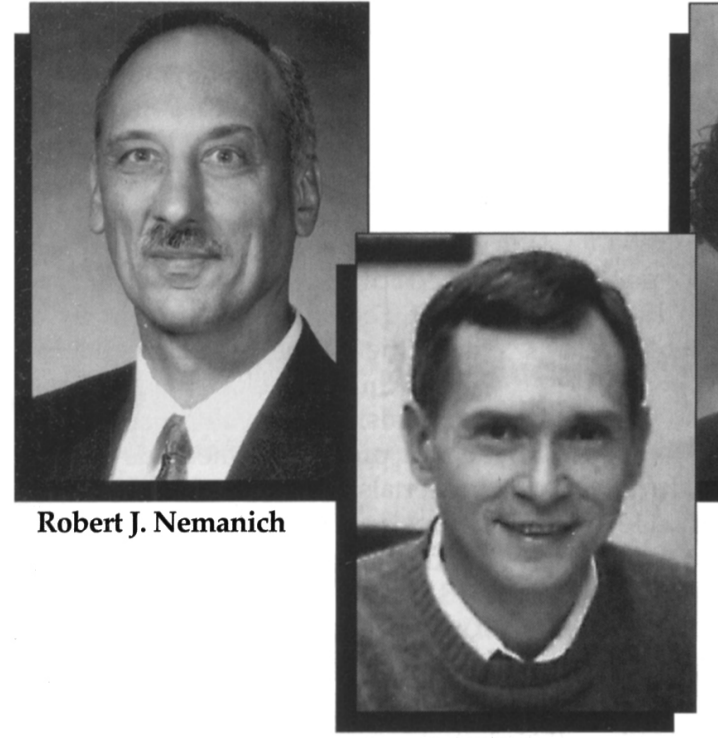

Ronald Gibala
Robert J. Nemanich (North Carolina State University) automatically assumes the position of the 1998 Materials Research Society president from his position as Vice President (President-Elect) in 1997. He succeeds Robert Hull from the University of Virginia who now serves MRS as immediate past president.

Beginning with the 1998 election, MRS members elect a Vice President (PresidentElect). The first elected Vice President is Ronald Gibala (University of Michigan). Chuang Chuang Tsai (Applied Komatsu Technology) has been elected for a twoyear term as secretary and Alan J. Hurd (Sandia National Laboratories) enters the second year of his two-year term as Treasurer. MRS Council has elected two councillors to serve one-year terms on the executive committee: Harry A. Atwater (California Institute of Technology) and Martin L. Green (Bell Laboratories, Lucent Technologies).

The newly elected MRS councillors for 1998 are Michael Aziz, Harvard University; Katayun Barmak, Lehigh University; David J. Eaglesham, Bell Laboratories, Lucent Technologies; Alexander H. King, State University of New York at Stony Brook; Karen Maex, IMEC, Belgium; and Alan I. Taub, Ford Motor Company (re-elected). They join the following current members of council: Cammy R. Abernathy, University of Florida; Harry A. Atwater; Theodore M. Besmann, Oak Ridge National Laboratory; Martin L. Green; Amy J. Moll,

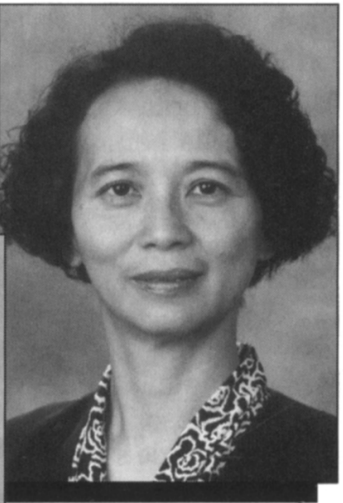

Chuang Chuang Tsai

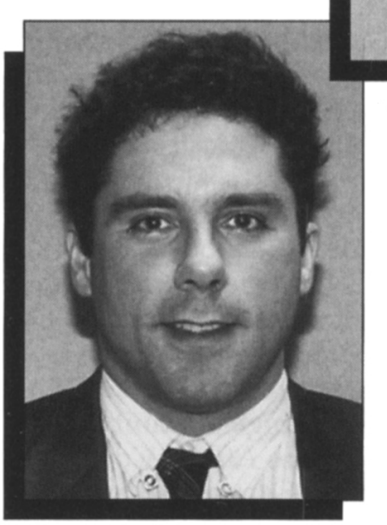

Harry A. Atwater

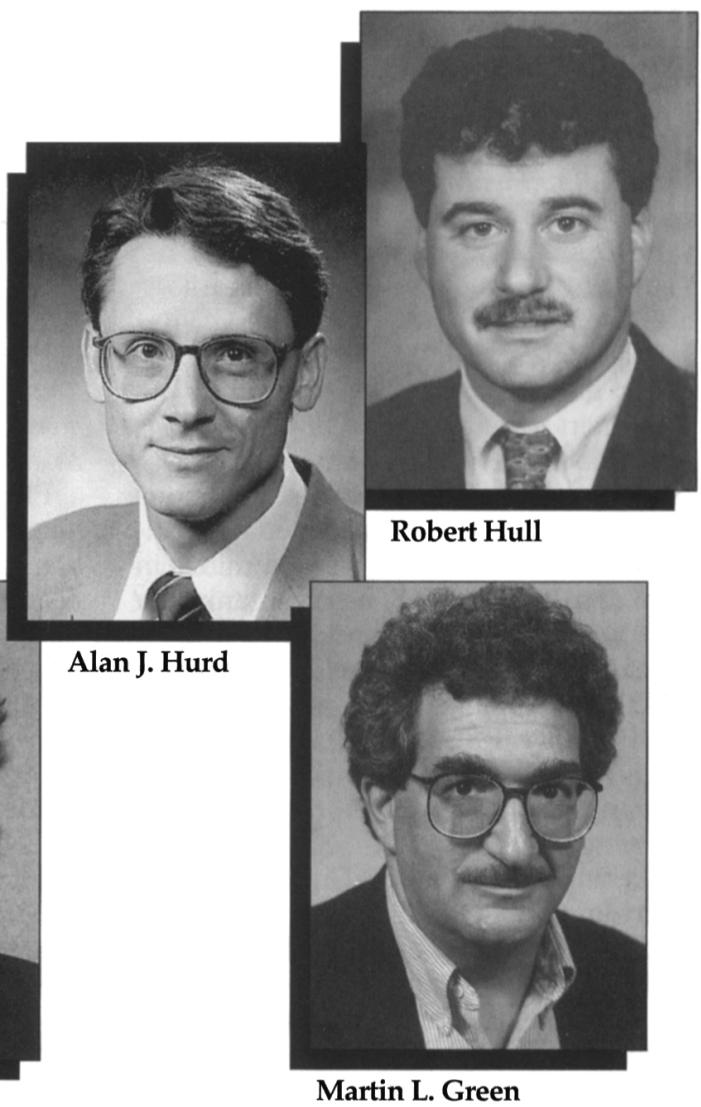

Hewlett Packard; Virginia M. Oversby, Stockholm, Sweden; Timothy D. Sands, University of California-Berkeley; Lyle H. Schwartz, Associated Universities Inc.; and James S. Williams, Australian National University.

\section{Robert J. Nemanich}

President

Robert J. Nemanich, professor of physics and an associate member of the Department of Materials Science and Engineering at North Carolina State University, coordinates an interdisciplinary research program involving postdoctoral research associates and undergraduate and graduate students from the departments of materials science, physics, and electrical engineering. With his main research interest area in electronic materials, Nemanich's current research topics include diamond and other wide-bandgap semiconductor surfaces and interfaces, heteroepitaxy on $\mathrm{Si}$, semiconductor surface cleaning and preparation, and amorphous and microcrystalline semiconductors.

After receiving his BS degree in physics from Northern Illinois University in 1969 and his $\mathrm{PhD}$ degree in physics from the University of Chicago in 1976, Nemanich worked at Xerox Palo Alto Research Center from 1976 to 1986 . He was involved with research, development, and research management in the Integrated Circuit and General Science Laboratories.

Within MRS, Nemanich served as vice president (president-elect) (1997), second vice president (1996), and, prior to that, as chair of the Continuing Education Committee for three years. He has served on the Publications and Program Committees, co-organized five MRS symposia, and co-chaired the 1989 MRS Fall Meeting.

\section{Ronald Gibala \\ Vice President \\ (President-Elect)}

Ronald Gibala is a professor in and former chair of the Department of Materials Science and Engineering at the University of Michigan. He directs the Center for High Temperature Structural Metallic Materials, an interdisciplinary program funded by the Air Force Office of Scientific Research. His current research 
interests are in the area of mechanical behavior of materials, particularly intermetallic alloys and related quasi-brittle materials.

After receiving his BS degree in metallurgical engineering from Carnegie Mellon University (1960) and his MS (1962) and PhD (1964) degrees in metallurgical engineering from the University of Illinois at Urbana-Champaign, Gibala taught at Case Western Reserve University from 1964 to 1984 and was associate director and director of the CWRU Materials Research Laboratory during the latter part of that time. He joined the University of Michigan in 1984.

Gibala has served on numerous advisory committees and participated in various professional societies. He served as councillor on the MRS Executive Committee in 1996 and 1997. In 1988, he co-organized a symposium on science and technology of refractory metals at the MRS Spring Meeting. He is one of the meeting chairs for the 1998 MRS Spring Meeting.

\section{Chuang Chuang Tsai \\ Secretary}

Chuang Chuang Tsai is Director of Engineering, Global CVD Product Management, at Applied Komatsu Technology (Santa Clara), an equipment manufacturer for the flat-panel display industry. Prior to joining AKT in 1997, she was a technical program manager at $\mathrm{dpi} X$, a spin-off from Xerox Palo Alto Research Center, developing flat-panel display and medical-imaging technology, and, from 1978 to 1996 , she worked at Xerox-PARC. Her research interests include materials, process, and devices of amorphous, microcrystalline, and polycrystalline silicon; plasmaenhanced chemical vapor deposition; laser crystallization; hydrogen effect on film growth and defect passivation; thin-film transistors and diodes; metal/silicon interfaces; and optical recording. Her current focus is on active-matrix liquid crystal display and medical-imaging technology.

Tsai received her PhD degree from the University of Chicago in 1978. She was a recipient of the Xerox Corporate Research Group (CRG) Excellence in Science and Technology Award in 1989 and 1993. She is co-holder of U.S. patents, a co-author of over 100 scientific papers, and co-editor of six symposium proceedings on the topics of microcrystalline and nanocrystalline semiconductors, and integratedcircuit and solid-state technology.

Tsai has co-organized three MRS symposia, and has served on the Meetings Quality Subcommittee, the Program Development Subcommittee, the Program Committee, and the editorial board of MRS Bulletin. She has co-chaired the 1996 MRS Spring Meeting.

\section{Alan J. Hurd \\ Treasurer}

Alan J. Hurd is manager of the Theoretical and Computational Materials Department at Sandia National Laboratories and adjunct professor of physics at the University of New Mexico. His research interests center around complex fluids, including colloidal physics, sol-gel film technology, and the physics of dipcoating. His other research interests include fractals, two-dimensional phases, aerosols, imaging ellipsometry, granular materials, and small-angle scattering.

Prior to joining Sandia in 1984, Hurd taught physics at Brandeis University. He has served on advisory groups for Los Alamos National Laboratory, the National Research Council, the National Renewable Energy Laboratory, and the University of New Mexico. He has been awarded three research awards by the Department of Energy. Hurd's BS degree from Colorado School of Mines and his 1981 PhD degree from the University of Colorado are in physics.

Hurd's contributions to MRS include Treasurer (1997), participation on the Long-Range Planning Committee, the Academic Affairs Committee, the Membership Committee, and the former MRS Bulletin Subcommittee; symposia organizer; short course instructor; and chair of the 1994 Spring Meeting.

\section{Robert Hull}

\section{Immediate Past President}

Robert Hull is an associate professor in the Materials Science and Engineering Department at the University of Virginia. His research interests in the past decade have included superionic conductors, radiation damage mechanisms, metallic superlattices, tribology, ceramic superconductors, ion implantation, x-ray mirror materials, and quantum wires and dots. The primary focus of his research, however, is in electronic materials, particularly the structure and properties of interfaces, defects, and thin films. The principal experimental tools used in his research are electron microscopy and focused ion beams.

Prior to joining the University of Virginia, Hull worked in the Materials Research Department at AT\&T Bell Laboratories and the Materials Characterization Department at Hewlett Packard Laboratories. Hull received his $\mathrm{PhD}$ degree in materials science from Oxford, England, in 1983.

Along with serving MRS as president
(1997), Hull served as first vice president (1996), second vice president (1995), on Council from 1992 to 1994, and on the Publications, Program, Academic Affairs, and Continuing Education Committees. He co-chaired three MRS symposia and was a chair for the 1990 MRS Fall Meeting.

\section{Harry A. Atwater \\ Councillor}

Harry A. Atwater is associate professor of applied physics at the California Institute of Technology. He focuses his research on the synthesis and characterization of new thin-film electronic and photonic materials, and development of new analytic and processing methods for electronic materials. He has active interests in ion-surface interactions and epitaxial growth of semiconductors, semiconductor nanocrystals, as well as in situ analytic tools for thin-film growth such as reflection electron energy loss spectroscopy.

Prior to joining Caltech as assistant professor in 1988, Atwater received a PhD degree in electrical engineering from the Massachusetts Institute of Technology in 1987. He was an IBM Postdoctoral Fellow in applied physics at Harvard University (1987-1988) and he received an NSF Presidential Young Investigator Award in 1989. For 15 years, Atwater has been an active contributor to Fall and Spring MRS Meetings. He received an MRS Graduate Student Award in 1985, co-organized four MRS technical symposia, co-chaired the 1997 MRS Fall Meeting, and has served as chair of the MRS Graduate Student Awards Subcommittee.

\section{Martin L. Green \\ Councillor}

Martin L. Green of Bell Laboratories / Lucent Technologies is involved with the application of integrated processing to deep submicron ultralarge-scale integration (ULSI) technology. He is concerned with the processing, structure, and electrical properties of ultrathin gate dielectric materials.

Green received his $\mathrm{PhD}$ degree in materials science in 1978 from the Massachusetts Institute of Technology. He has authored or co-authored over 70 publications, has been granted nine patents, and is the editor of seven books.

For several years, Green chaired or cochaired the MRS symposium on Rapid Thermal and Integrated Processing. He co-chaired the 1993 MRS Spring Meeting, has served on the MRS Program Committee since 1994, and is a member of the MRS Bulletin Book Review Board. 